\title{
Effect of thermal therapy using hot water bottles on brain natriuretic peptide in chronic hemodialysis patients
}

\author{
Yoko Uchiyama-Tanaka* \\ Yoko Clinic, Kitakyushu, Japan; yoko-uchiyama-tanaka@yoko-clinic.net
}

Received 14 May 2011; revised 15 August 2012; accepted 28 August 2012

\begin{abstract}
Introduction: The use of repeated thermal therapy for improving the symptoms of chronic heart failure (CHF) has been recently demonstrated. Usually, thermal therapy requires an infrared dry sauna. However, it is difficult for small clinics to acquire such an expensive and extensive system. The author assessed the efficacy of its substitution with hot water bottles. Moreover, there are no prior studies demonstrating the efficacy of thermal therapy in hemodialysis patients with chronic heart failure. Methods: The author evaluated plasma brain natriuretic peptide (BNP) levels in 98 hemodialysis patients in a clinic. A total of nine patients whose BNP levels were more than $500 \mathrm{pg} / \mathrm{mL}$ agreed to be enrolled in this study and received thermal therapy using hot water bottles. Results: Plasma BNP levels, a potential marker for CHF, tended to decrease $(891 \pm 448 \mathrm{pg} / \mathrm{mL}$ to $680 \pm 339 \mathrm{pg} / \mathrm{mL})$, but the difference was not significant $(P=0.0845)$. The oral temperature changed from $36.44^{\circ} \mathrm{C} \pm 0.45^{\circ} \mathrm{C}$ to $37.04^{\circ} \mathrm{C} \pm 0.48^{\circ} \mathrm{C}\left(+0.597^{\circ} \mathrm{C}, P<0.0001\right)$. No side effects were experienced during the therapy. Moreover, most patients had an improvement in their symptoms and the ability to perform activities of daily living. Conclusion: Thermal therapy using hot water bottles is very safe and tends to reduce plasma BNP levels in hemodialysis patients with CHF.
\end{abstract}

Keywords: BNP; Brain Natriuretic Peptide; Chronic Heart Failure; Chronic Kidney Disease; Hemodialysis; Hot Water Bottle Thermal Therapy

\section{INTRODUCTION}

Chronic heart failure (CHF) is a major serious complication for hemodialysis patients [1-3]. Kihara et al.

\footnotetext{
${ }^{*}$ The author declares no conflict of interest.
}

and Miyata et al. recently reported that repeated thermal therapy could improve hemodynamics and symptoms in patients with CFH [4-6]. The therapy requires an infrared-ray dry sauna because the temperature needs to be maintained evenly at $60^{\circ} \mathrm{C}$. Unfortunately, it is difficult for small clinics to acquire such an expensive and extensive system. Tei et al. [4-6] proposed warm water baths as a substitute for saunas, which can warm the body without overloading the heart.

This study assessed whether thermal therapy for CHF using hot water bottles can be used as a substitute for infrared-ray dry sauna. Moreover, the author also assessed whether thermal therapy is useful for hemodialysis patients with CHF as there have been no studies demonstrating the efficacy of thermal therapy in this patient population. BNP is a superior parameter for assessing left ventricular (LV) function rather than volume overload of heart failure patients with normal kidney function [7]. Hemodialysis patients are loading of volume every day. This study used BNP as parameter for assessing LV function.

\section{MATERIALS AND METHODS}

\subsection{Study Design and Participants}

The study procedures were in accordance with the guidelines of the 2000 Declaration of Helsinki for human experimentation. All subjects provided informed consent. Nine out of 98 inpatients undergoing hemodialysis treatment in November 2007 at the Hosoe clinic, and whose BNP levels were more than $500 \mathrm{pg} / \mathrm{mL}$ were enrolled in this study. Patients with arterial ventricular stenosis and other outflow obstacle heart disease were excluded, as such thermal therapy is contraindicated in these conditions [4,5]. None of the nine patients had any signs, symptoms, or history of cancer or any active inflammatory disease.

\subsection{Laboratory Measurements}

To evaluate brain natriuretic peptide (BNP) levels after 
hemodialysis, blood samples of the patients were collected in the supine position. Plasma samples were prepared within 30 minutes after collection using a precooled centrifuge. Extracted plasma samples were frozen immediately and stored at $-20^{\circ} \mathrm{C}$ until analysis. Plasma BNP concentrations were measured by an immunoradiometric assay specific for human BNP using a commercial kit (Shionogi BNP kit; Shionogi Co. Ltd., Osaka, Japan). The author again collected blood samples 3 months later at the end of the follow-up period. Oral temperature was measured before and after each therapy session.

\subsection{Thermotherapy Using Hot Water Bottles}

The author interviewed and evaluated the ability to perform activities of daily living (ADL), and classified the heart failure using the classification of New York Heart Association (NYHA) before and after this study.

Before this study, all patients were treated with betablockers, angiotensin II-converting enzyme inhibitors, and angiotensin II-receptor blockers according to the treatment guideline for the evaluation and management of CHF [8]. Drug treatment was continued throughout the study. After an examination that involved measuring patients' dry weight, and assessing X-ray images and other clinical parameters, such as blood pressure, patients received thermal therapy using hot water bottles. This therapy is derived from the thermal therapy using an infrared-ray dry sauna invented by Kihara et al. and Miyata et al. [4,5]. Initially, patients received a hot water foot bath $\left(44^{\circ} \mathrm{C}\right)$ for 30 minutes. Subsequently, patients were then asked to lie down on a bed with hot water bottles and were wrapped in a blanket for another $30 \mathrm{~min}$ utes. This procedure was repeated three times per week after hemodialysis for a total follow-up period of 3 months.

\subsection{Statistical Analysis}

Values are expressed as the mean \pm SD. Student's $t$-test was used for all comparisons. $P$-values less than 0.05 were considered significant.

\section{RESULTS}

Demographic and clinical characteristics of the patients are summarized in Tables 1 and 2, respectively. Before the study, the author assessed the ability of patients to perform ADL. If, despite high BNP levels, the patients did not complain of NYHA-defined heart failure-related symptoms, it was speculated that it might have been difficult for hemodialysis patients with many other aches and joint problems to notice the symptoms related to heart failure. Each patient underwent the thermal therapy three times per week after hemodialysis for 3 months. The nine patients who were included in the analysis (two men and seven women; mean age, $74.2 \pm$ 14.6 years old; average duration of hemodialysis, $8.3 \pm$ 6.2 years) were able to continue thermotherapy and were observed for 3 months. Plasma BNP levels in the peripheral blood changed from $891 \pm 448 \mathrm{pg} / \mathrm{mL}$ (range 419 $1627 \mathrm{pg} / \mathrm{mL}$ ) to $680 \pm 339 \mathrm{pg} / \mathrm{mL}$ (range $208-1100$ $\mathrm{pg} / \mathrm{mL})$ after 3 months $(P=0.0845)$. The change in plasma BNP levels was not significant, but the levels tended to decrease. The oral temperature changed from $36.44^{\circ} \mathrm{C} \pm 0.45^{\circ} \mathrm{C}$ to $37.04^{\circ} \mathrm{C} \pm 0.48^{\circ} \mathrm{C}\left(+0.597^{\circ} \mathrm{C}, P<\right.$ 0.0001 ). After 3 months of thermal therapy, the ADL score was improved in all patients (Table 2).

Other clinical parameters, such as blood pressure, dry weight, anemia, and cardiothoracic ratio did not change significantly (data not shown). Results of the echocardiogram tests conducted before and after the study period revealed no significant change in the ejection fraction and other associated parameters (data not shown). No side effects were experienced during the therapy.

Table 1. Demographic characteristics, and present heart disease and other conditions of the study population.

\begin{tabular}{ccccc}
\hline Case & Age (years) & Sex & Duration of hemodialysis (years) & Heart disease \\
\hline 1 & 79 & Female & 5.0 & SN/AR moderate \\
2 & 79 & Male & 6.0 & CGN/MR mild \\
3 & 53 & Female & 15.0 & DM/LVH \\
4 & 83 & Female & 3.0 & DM/OMI \\
5 & 73 & Female & 13.0 & PKD/MR and LVH mild \\
6 & 80 & Female & 5.0 & DM/MR and AR \\
7 & 47 & Male & 6.0 & SN/MR \\
8 & 90 & Female & 2.0 & MR/AR and LVH
\end{tabular}

$A F$ atrial fibrillation, $A R$ aortic valve regurgitation, $C G N$ chronic glomerular nephropathy, $D M$ diabetic nephropathy, $L V H$ left ventricular hypertrophy, $M R$ mitral valve regurgitation, $O M I$ old myocardial infarction, $P K D$ polycystic kidney disease, $S N$ sclerosis nephropathy. 
Table 2. Demographic characteristics of the study population and the experienced symptom change.

\begin{tabular}{|c|c|c|c|c|c|}
\hline Case & $\begin{array}{l}\text { Age } \\
\text { (years) }\end{array}$ & Sex & Ability to perform $\mathrm{ADL}^{\dagger}$ & Change in ability to perform ADL & $\begin{array}{l}\text { NYHA heart failure } \\
\text { classification change }\end{array}$ \\
\hline 1 & 79 & Female & Pain in the right knee ${ }^{*}$ & Disappeared & $\mathrm{II} \rightarrow \mathrm{I}$ \\
\hline 2 & 79 & Male & No symptoms & No change & $\mathrm{II} \rightarrow \mathrm{I}$ \\
\hline 3 & 53 & Female & Chill, heart palpitation at rest & Disappeared (both symptoms) & $\mathrm{II} \rightarrow \mathrm{I}$ \\
\hline 4 & 83 & Female & No symptoms & No change & $\mathrm{I} \rightarrow \mathrm{I}$ \\
\hline 5 & 73 & Female & $\begin{array}{l}\text { Right hand sclerosis }(10 / 10) \text {; abdominal } \\
\text { pain after abdominal surgery }(10 / 10) \text {; pain } \\
\text { in the left knee }(10 / 10) \text {; could not perform } \\
\text { housework }\end{array}$ & $\begin{array}{l}\text { Improvement in hand movement } \\
(6 / 10) \text {, abdominal pain }(3 / 10) \text {, knee } \\
\text { pain }(5 / 10) \text {; could perform some } \\
\text { housework }\end{array}$ & NA \\
\hline 6 & 80 & Female & Back pain & Disappeared $^{\S}$ & NA \\
\hline 7 & 47 & Male & Could not speak after brain hemorrhage & $\begin{array}{l}\text { Became more alert and started } \\
\text { speaking }\end{array}$ & NA \\
\hline 8 & 90 & Female & Pain in both knees & Disappeared $^{* *}$ & NA \\
\hline 9 & 84 & Female & Pain in the left shoulder, toothache & Disappeared $^{\dagger \dagger}$ & NA \\
\hline
\end{tabular}

$A D L$ activities of daily living, NYHA New York Heart Association. ${ }^{*}$ The duration of knee pain was over a year; ${ }^{\dagger}$ Symptoms were assessed on a scale from 1 (minimal) - 10 (maximum); ${ }^{*}$ The patient could not walk for 100 meters because of knee pain; after the study the patient could walk $3 \mathrm{~km} ;{ }^{\S}$ The patient could not walk and used a wheelchair; after the study the patient could walk with a cane; ${ }^{\text {TT }}$ The patient could not speak to complain of any symptoms for 5 years, after the study the patient could speak; ${ }^{* *}$ The patient could not walk because of knee pain and used a wheelchair; after the study the patient can walk with a cane; ${ }^{\dagger \dagger}$ The patient is bedridden.

\section{DISCUSSION}

Results of this study suggest that the ability to perform ADL of hemodialysis patients can be improved with the use of hot water bottle thermal therapy, and that such therapy can help to decrease plasma BNP levels. This is the first study to demonstrate that mild thermal therapy is an effective, relatively safe, and easy way to improve the ability to perform ADL, and may also improve LV function in CHF patients.

Thermal therapy, also known as Waon therapy, is defined as "therapy in which the entire body is warmed in an evenly heated chamber for $15 \mathrm{~min}$ at a temperature that soothes the mind and body, and after the deep body has increased by approximately $1.0^{\circ} \mathrm{C}-1.2^{\circ} \mathrm{C}$, the soothing warmth continues at rest for an additional $30 \mathrm{~min}$, with fluids supplied at the end to replace the loss from perspiration" [4].

According to Tei [4-6], although medical progress in the 20th century has been outstanding, there is still no way of determining the magnitude of a patient's internal suffering and conflict. Medical staff cannot understand the extent of pain, tension, and stress experienced by patients who receive life-saving therapies, especially CHF patients ineligible for operation. Kihara et al. and Miyata et al. developed thermal therapy for such patients, and it has been found to improve hemodynamics and decrease serum BNP levels, arrhythmia, and sympathetic nervous system activity, which occurs with severe cardiac failure [4-6]. Moreover, this method is an effective treatment for Sjogren disease and other lifestyle-related diseases, such as hypertension, diabetes mellitus, hyperlipidemia, obesity, and smoking-related diseases $[9,10]$.
Warming the body has been shown to relieve the sympathetic nervous system [5-7]. Furthermore, it has been shown that it might also improve the immune system [11-13]. Warming the body using hot water bottles warms the patient slowly and does not burden weak patients [11]. In the current medical practice, the medical staff often does not have the sufficient time to see and talk to patients. Talking and listening to a suffering patient enables them to relax and develop a trusting relationship with the medical team. The time spent with the patient by the medical staff during the thermal treatment might be the most important and effective part of this therapy.

In the present study, most patients reported alleviation of pain and the symptoms impacting the ability to perform ADL during the thermal therapy. Warming decreases activity of the sympathetic nervous system and opens peripheral blood vessels, resulting in relaxation of tendons and muscles [4-6]. Reducing the pain also decreases activity of the sympathetic nervous system and increases the patient's trust in the medical staff, resulting in more efficient medical care.

There are no previous studies on the appropriate duration of the thermal treatment. The effect of sauna therapy after 2 - 4 weeks has been reported [4-6], and the authors suggest that the therapy was effective for improving the ability to perform ADL in severe heart failure patients when performed once a day for 3 - 4 days a week. In addition, this method is very easy to implement; hence, the length of each session can vary as required.

Measuring BNP levels is the established parameter for assessing LV function with normal kidney function [7]. However, there are conflicting results concerning as- 
sessing chronic renal function, especially in dialysis patients. Many reports recommend using the BNP level as a possible prognostic marker for cardiac disease even in chronic kidney disease (CKD) [14-17]. Park et al. recently reported that the BNP level is a useful marker for assessing the risk of new cardiac events in patients with CKD [18]. There are few reports recommending BNP levels as a prognostic marker for $\mathrm{CHF}$ in $\mathrm{CKD}$ because BNP levels in hemodialysis patients vary within a large range. Moreover, the level of BNP in hemodialysis patients can change daily $[14,19]$. Although a few reports suggest that the normal BNP level is below $100 \mathrm{pg} / \mathrm{dL}$ even in hemodialysis patients [20], other reports most commonly suggest a range of $150-300 \mathrm{pg} / \mathrm{dL}$ for patients without heart disease, but this level is not consistently reported and is based on cross-sectional studies [21,22].

There have been no reports on longitudinal BNP levels in hemodialysis patients. In the present study, the author evaluated BNP levels in hemodialysis patients by means of a longitudinal study. In most people without CKD, BNP enhanced LV systolic and diastolic functions. However, the most precise and convenient method for the evaluation of diastolic LV function remains controversial. It is difficult to evaluate diastolic LV function by general ultrasonography [23]. Echocardiography was performed for all patients in the present study, but patients' ability to perform ADL was very poor and correct posture could not be obtained. Some patients also had lung disease with severe calcifications. Among patients on hemodialysis, there are numerous patients with normal ejection

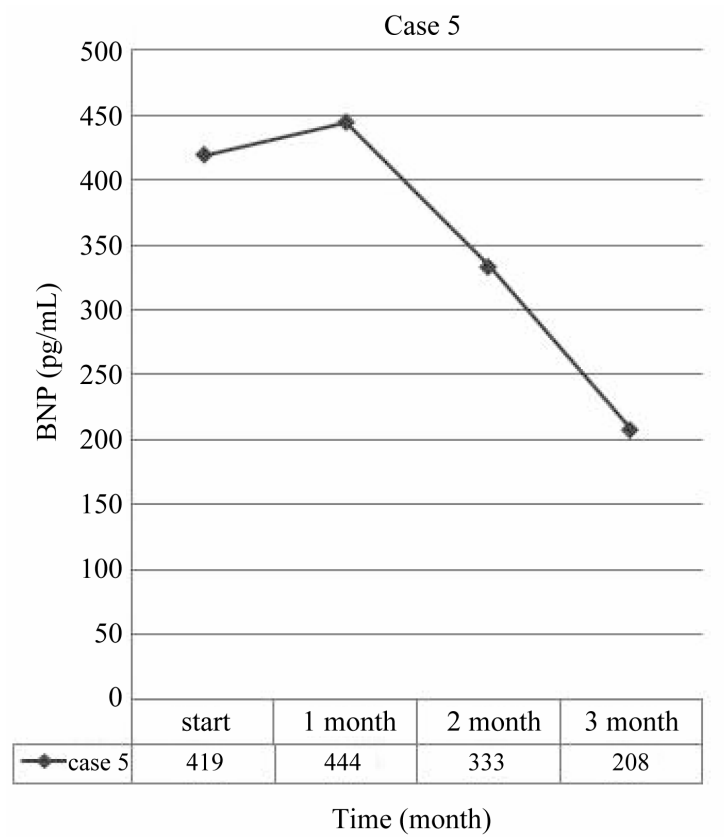

fraction, who also have restricted function of left ventricle because of chronic volume overload, volume change, hypertension, and/or amyloidosis.

The timing for measuring the BNP level is very important. In the present study, the author compared BNP levels in the same patients at different times. Before hemodialysis, weight gain (water volume) values differed each time, but after hemodialysis, dry weight values were fixed for each patient. The BNP level was found to have less of a relationship to water volume, but the levels were measured before and after hemodialysis, and were clearly different. The author evaluated the BNP levels after hemodialysis. This might be the reason that there was no significant change in BNP levels before and after the study. Interestingly, the BNP level could be used as a marker for LV function in some patients, as shown in the two patients whose BNP levels clearly decreased in the present study (Figure 1). However, there is no consensus on the best time to measure the BNP levels in hemodialysis patients, whether it is at the start or end of the week, or pre- or post-hemodialysis. The author decided to measure BNP levels after hemodialysis when weights were fixed and other parameters were stable. It was difficult to find the most convenient and valid parameter to determine heart function in hemodialysis patients. BNP levels decreased in this study, but the decrease was not statistically significant; however, some patients experienced significant decreases in BNP (Figure 1).

There were several limitations to this study. The number of patients was very limited and the increase of body

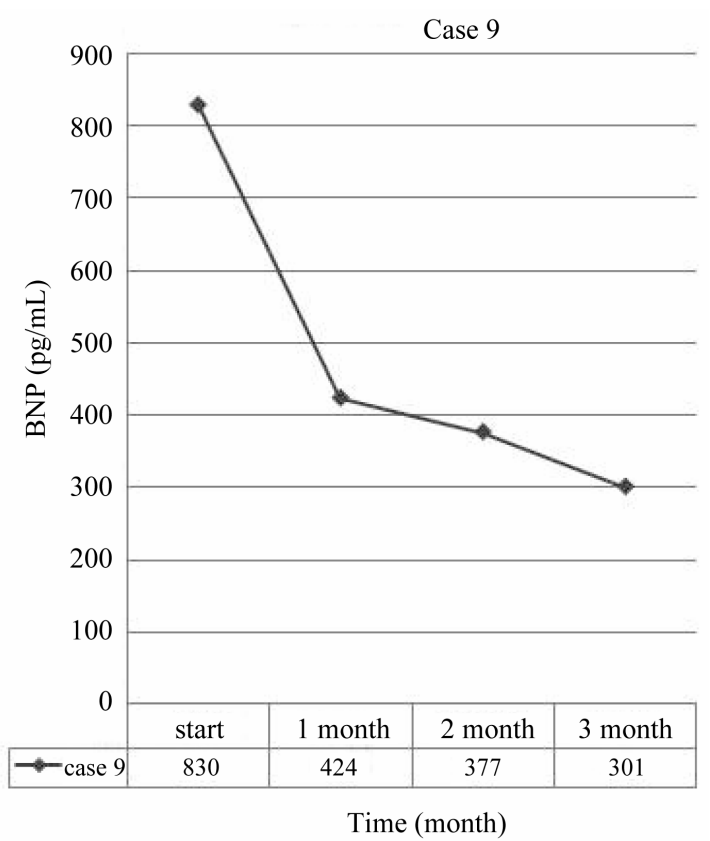

Figure 1. BNP levels before and after the present study of the two patients whose BNP clearly decreased. BNP brain natriuretic peptide. 
temperature in the study was $0.597^{\circ} \mathrm{C}$, less than $1.0^{\circ} \mathrm{C}$ suggested by Tei's et al. Furthermore, the renal impairment of hemodialysis patients in the present study may lead to accumulation of levels of N-terminal proBNP [7, $15,24,25]$. Moreover, this study included a small population that was followed up for a very limited duration.

\section{CONCLUSION}

Using such a convenient and simple method for thermal therapy, the author demonstrated an improvement in patients who suffered from pain and experienced difficulty with mobility. The therapy also could be conducted without the side effects associated with other effective therapies. The author concludes that thermal therapy using hot water bottles is very safe and tends to decrease plasma BNP levels in hemodialysis patients with CHF.

\section{KEY SUMMARY POINTS}

- The author assessed the efficacy of substituting infrared dry sauna with hot water bottle thermal therapy.

- A total of nine patients whose brain natriuretic peptide (BNP) levels were more than $500 \mathrm{pg} / \mathrm{mL}$ agreed to be enrolled in this study and received thermal therapy using hot water bottles.

- Plasma BNP levels tends to decrease $(891 \pm 448$ $\mathrm{pg} / \mathrm{mL}$ to $680 \pm 339 \mathrm{pg} / \mathrm{mL})$, but there was no significant difference $(P=0.0845)$. The oral temperature changed $36.44^{\circ} \mathrm{C} \pm 0.45^{\circ} \mathrm{C}$ to $37.04^{\circ} \mathrm{C} \pm 0.48^{\circ} \mathrm{C}$ $\left(+0.597^{\circ} \mathrm{C}, P<0.0001\right)$.

- Most patients showed an improvement in their symptoms and ability to perform activities of daily living.

- The author concludes that thermal therapy using hot water bottle is a very safe and tends to reduce plasma BNP levels in hemodialysis patients with chronic heart failure.

\section{ACKNOWLEDGMENTS}

Dr. Uchiyama-Tanaka is the guarantor for this article, and takes responsibility for the integrity of the work as a whole.

Open Access. This article is distributed under the terms of the Creative Commons Attribution Noncommercial License which permits any noncommercial use, distribution, and reproduction in any medium, provided the original author(s) and source are credited.

\section{REFERENCES}

[1] Parfery, P.S. and Foley, R.N. (1999) The clinical epidemiology of cardiac disease in chronic heart failure. Journal of the American Society of Nephrology, 10, 16061615.

[2] Hamett, J.D., Foley, R.N., Kent, G.M., et al. (1995) Congestive heart failure in dialysis patients: Prevalence, incidence, prognosis and risk factors. Kidney International,

\section{7, 884-890. doi:10.1038/ki.1995.132}

[3] Ronco, C., Happio, M., House, A.A., et al. (2008) Cardiorenal syndrome. Journal of the American College of Cardiology, 52, 1527-1539. doi:10.1016/j.jacc.2008.07.051

[4] Kihara, T., Miyata, M., Fukudome, T., et al. (2009) Waon therapy improves the prognosis of patients with chronic heart failure. Journal of Cardiology, 53, 214-218. doi:10.1016/j.jjcc.2008.11.005

[5] Miyata, M., Kihara, T., Kubozono, T., et al. (2008) Beneficial effects of Waon therapy on patients with chronic heart failure: Results of a prospective multicenter study. Journal of Cardiology, 52, 79-85. doi:10.1016/j.jjcc.2008.07.009

[6] Kihara, T., Biro, S., Ikeda, Y., et al. (2004) Effects of repeated sauna treatment on ventricular arrhythmia inpatients with chronic heart failure. Circulation Journal, 68, 1146-1151. doi:10.1253/circj.68.1146

[7] Wilkins, M.R., Redondo, J. and Brown, L.A. (1997) The natriuretic-peptide family. Lancet, 349, 1307-1310. doi:10.1016/S0140-6736(96)07424-7

[8] Hunt, S.A., Baker, D.W., Chin, M.H., American College of Cardiology/American Heart Association, et al. (2001) ACC/AHA guidelines for the evaluation and management of chronic heart failure in the adult: Executive summary. A Report of the American College of Cardiology/American Heart Association Task Force on Practice Guidelines (Committee to revise the 1995 Guidelines for the Evaluation and Management of Heart Failure). Journal of American College of Cardiology, 38, 2101-2113. doi:10.1016/S0735-1097(01)01683-7

[9] Tei, C., Prihara, K. and Fukudome, T. (2007) Remarkable efficacy of thermal therapy for Sjogren syndrome. Journal of Cardiology, 49, 217-219.

[10] Biro, S., Masuda, A., Kihara, T., et al. (2003) Clinical implications of thermal therapy in lifestyle-related diseases. Experimental Biology and Medicine, 228, 12451249 .

[11] Madarame, H. and Kawashima, A. (2006) Use of hot water bottles can improve lymphocytopenia. Biomedical Research, 27, 45-48. doi:10.2220/biomedres.27.45

[12] Toyabe, S., Iiai, T., Fukuda, M., et al. (1997) Identification of nicotinic acetylcholine receptors on lymphocytes in the periphery as well as thymus in mice. Immunology, 92, 201-205. doi:10.1046/j.1365-2567.1997.00323.x

[13] Watanabe, M., Tomiyama-Miyaji, C., Kainuma, E., et al. (2008) Role of alpha-adrenergic stimulus in stress-induced modulation of body temperature, blood glucose and innate immunity. Immunology Letters, 115, 43-49. doi:10.1016/j.imlet.2007.09.010

[14] Nishikimi, T., Futoo, Y., Tamano, K., et al. (2001) Plasma brain natriuretic peptide levels in chronic hemodialysis patients: Influence of coronary artery disease. American Journal of Kidney Disease, 37, 1201-1208. doi:10.1053/ajkd.2001.24523

[15] Austin, W.J., Bhalla, V., Hernandez-Arce, I., et al. (2006) Correlation and prognostic utility of B-type natriuretic peptide and its amino-terminal fragment in patients with chronic kidney disease. American Journal of Clinical Pa- 
thology, 126, 506-512. doi:10.1309/M7AAXA0J1THMNCDF

[16] McCullough, P.A., Duc, P., Omland, T., et al. (2003) Breathing not properly multinational study investigators. B-type natriuretic peptide and renal function in the diagnosis of heart failure: An analysis from the breathing not properly multinational study. American Journal of Kidney Disease, 41, 571-579. doi:10.1053/ajkd.2003.50118

[17] Naganuma, T., Sugimura, K., Wada, S., et al. (2002) The prognostic role of brain natriuretic peptides in hemodialysis patients. American Journal of Nephrology, 22, 437444. doi:10.1159/000065272

[18] Park, S., Cho, G.Y., Kim, S.G., et al. (2009) Brain natriuretic peptide levels have diagnostic and prognostic capability for cardio-renal syndrome type 4 in intensive care unit patients. Critical Care, 13, R70. doi:10.1186/cc7878

[19] Akiba, T., Tachibana, K., Togashi, M., et al. (1995) Plasma human brain natriuretic peptide in chronic renal disease. Clinical Nephrology, 44, S61-S64.

[20] Zoccali, C., Mallamaci, F., Benedetto, F.A., et al. (2001) Cardiac natriuretic peptides are related to left ventricular mass and function and predict mortality in dialysis patients. Journal of the American Society of Nephrology, 12, 1508-1515.
[21] Takami, Y., Horio, T., Iwashima, Y., et al. (2004) Diagnostic and prognostic value of plasma brain natriuretic peptide in non-dialysis-dependent CRF. American Journal of Kidney Diseases, 44, 420-428.

[22] Goto, T., Takase, H., Toriyama, T., et al. (2002) Increased circulating levels of natriuretic peptides predict future cardiac event in patients with chronic hemodialysis. $\mathrm{Ne}$ phron, 92, 610-615. doi:10.1159/000064100

[23] Gardin, J.M., Leifer, E.S., Fleg, J.L., HF-ACTION Investigators, et al. (2009) Relationship of doppler-echocardiographic left ventricular diastolic function to exercise performance in systolic heart failure: The HF-ACTION study. American Heart Journal, 58, S45-S52. doi:10.1016/j.ahj.2009.07.015

[24] deFilippi, C.R., Fink, J.C., Nass, C.M., et al. (2005) Nterminal pro-B-type natriuretic peptide for predicting coronary disease and left ventricular hypertrophy in asymptomatic CKD not requiring dialysis. American Journal of Kidney Diseases, 46, 35-44. doi:10.1053/j.ajkd.2005.04.007

[25] Mark, P.B., Stewart, G.A., Gansevoort, R.T., et al. (2006) Diagnostic potential of circulating natriuretic peptides in chronic kidney disease. Nephrology Dialysis Transplantation, 21, 402-410. doi:10.1093/ndt/gfi187 